\title{
Effect of tool geometry on friction stir spot welding of polypropylene sheets
}

\author{
M. K. Bilici* \\ Marmara University, Technical Education Faculty, Department of Materials Technology, 34722 Istanbul, Turkey
}

Received 8 February 2012; accepted in revised form 3 May 2012

\begin{abstract}
The effects of tool geometry and properties on friction stir spot welding properties of polypropylene sheets were studied. Four different tool pin geometries, with varying pin angles, pin lengths, shoulder diameters and shoulder angles were used for friction stir spot welding. All the welding operations were done at the room temperature. Lap-shear tensile tests were carried out to find the weld static strength. Weld cross section appearance observations were also done. From the experiments the effect of tool geometry on friction stir spot weld formation and weld strength were determined. The optimum tool geometry for $4 \mathrm{~mm}$ thick polypropylene sheets were determined. The tapered cylindrical pin gave the biggest and the straight cylindrical pin gave the lowest lap-shear fracture load.
\end{abstract}

Keywords: processing technologies, industrial applications, mechanical properties, polymer welding, friction stir spot welding

\section{Introduction}

The friction stir welding (FSW) process was developed by TWI in 1991 for joining aluminium alloys [1]. Subsequently this welding process has been used for joining magnesium [2], titanium [3] and copper alloys [4], stainless steels [5], steels [6] and thermoplastics [7]. Friction stir spot welding (FSSW) is a version of the FSW process. It was developed in the automotive industry as an alternative for resistance spot welding of aluminium sheets in 2001 [8].

The FSSW process consists of three phases; plunging, stirring and retracting as shown in Figure 1. The process starts with the spinning of the tool at a high rotational speed. Then the tool is forced into the workpiece until the shoulder of the tool plunges into the upper workpiece. The plunge movement of the tool causes material to expel as shown in Figures $1 \mathrm{a}$ and $1 \mathrm{~b}$. When the tool reaches the predetermined depth, the plunge motion ends and the stir- ring phase starts. In this phase, the tool rotates in the workpieces without plunging. Frictional heat is generated in the plunging and the stirring phase and, thus, the material adjacent to the tool is heated and softened. The softened upper and lower workpiece materials mix together in the stirring phase. The shoulder of the tool creates a compressional stress on the softened material. A solid-state joint is formed in the stirring phase. When a predetermined bonding is obtained, the process stops and the tool is retracted from the workpieces. The resulting weld has a characteristic keyhole in the middle of the
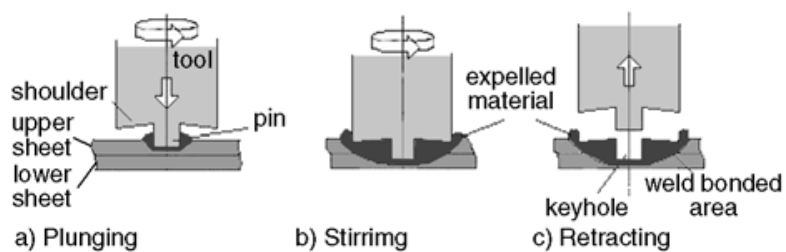

Figure 1. Three phases of friction stir spot welding process, (a) plunging, (b) stirring and (c) retracting 
joint as shown in Figure 1c. FSSW has been succesfully applied to aluminium $[9,10]$, magnesium [11] and steel [12] sheets, but there are very few publications on polymer FSSW applications [13-16].

The welding parameters and the tool geometry affect friction stir welding and friction stir spot welding stir zonestir zone formation and weld strength [17]. The tool consists of two parts [18]: the shoulder and the pin. The pin generates friction heat, deforms the material around it and stirs the heated material [19]. In FSSW of metals the diameters of the pin [20], the pin angle [21], pin thread orientation [22], pin length [23] and pin profile [24] were found important in stir zonestir zone formation. The shoulder of the tool generates heat during the welding process, forges the heated material, prevents material expulsion and assists material movement around the tool [25]. The diameters of the shoulder and its concavity are also important in friction stir spot welding [26].

Based on the observations of the FSSW macrostructures, the weld zone of a FSSW joint is schematically illustrated in Figure 2. From the appearance of the weld cross section, two geometrical characteristics of the weld may be identified [27, 28]. The first is the thickness of the weld stir zonestir zone $(x)$ which is an indicator of the weld bond area (Figure 2). The weld bond area increases with the stir zonestir zone thickness. The second is the thickness of the upper sheet under the shoulder indentation (y). These gerometircal characteristics determine the strength of a FSSW joint $[18,19]$. There are numerous papers concerning the FSSW parameters which affect the joint geometry and the weld strength $[16,29,30]$.

The quality of a spot weld is usually determined by a lap-shear test [31]. Standard lap-shear tests are used to find the joint strength of a resistance spot weld [32]. A standard for mechanical strength test for FSSW joints is not available presently. There-

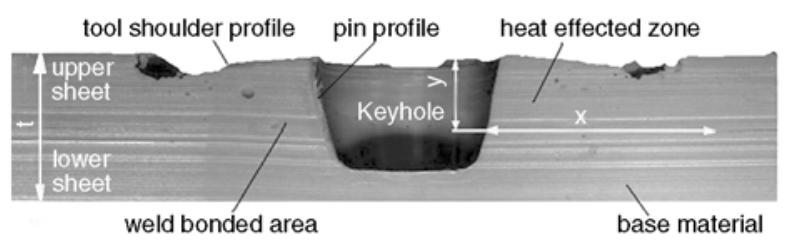

Figure 2. Schematic illustration of the cross section of a friction stir spot weld. $x$ : stir zone thickness, $y$ : the thickness of the upper sheet and $t$ : total materials thickness fore, in this study, the lap-shear test was used to determine the weld strength.

In FSW of metals improper welding parameters and tool geometry cause low mechanical strength and weld defects [33]. Therefore, in FSSW the welding parameters (tool rotational speed, dwell time, delay time, plunge depth and plunge rate) and the tool geometry (pin diameter, pin length, pin angle, pin profile, shoulder diameter and shoulder concavity angle) must be selected optimally [34]. There are a few studies about the FSSW tool geometry effects on thermoplastic sheets [13]. Thus, this study was intended to explain the tool geometry effects on FSSW of polypropylene sheets. The weld stir zone formation and lap-shear fracture loads were examined to reveal the tool effects.

\section{Experiments}

In this investigation $4 \mathrm{~mm}$ thick polypropylene sheets were used. Polypropylene sheets were purchased from SIMONA AG, Gemany (Tensile yield stress $34 \mathrm{MPa}$ or lap shear fracture load $4500 \mathrm{~N}$ ). 60 $\times 150 \mathrm{~mm}$ lap-shear specimens were cut from the sheets. In order to develop the FSSW tests, a properly designed clamping fixture was utilized to fix the specimens. The steel plates comprising the fixture ensure a uniform pressure distribution on the fixed specimens. Additionally, proper backing sheets were used in order to obtain the desired lap joints. A specimen had a $60 \times 60 \mathrm{~mm}$ overlap area. The specimens were welded in a milling machine. The tools used in welding operations were machined from SAE 1040 steel and heat treated to 40 Rockwell C Hardness Conversion. The tool dimensions are shown in Figure 3. Four different tool pin profiles (straight cylindrical, tapered cylindrical, threaded cylindrical and square) were used to fabricate the joints (Fig-

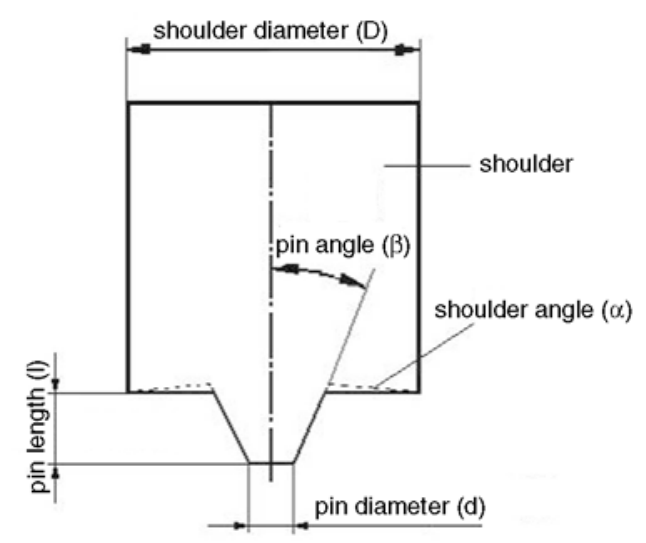

Figure 3. FSSW tool design showing geometric parameters 
Table 1. The FSSW tool dimensions

\begin{tabular}{|l|c|c|c|}
\hline \multicolumn{1}{|c|}{ Dimensions } & Symbol & Units & Ranges \\
\hline Shoulder diameter & $D$ & millimeter $[\mathrm{mm}]$ & $10-35$ \\
\hline Pin length & $l$ & millimeter $[\mathrm{mm}]$ & $3.8-6.5$ \\
\hline Pin angle & $\alpha$ & $\circ$ & $0-25$ \\
\hline Shoulder angle & $\beta$ & $\circ$ & $0-12$ \\
\hline
\end{tabular}

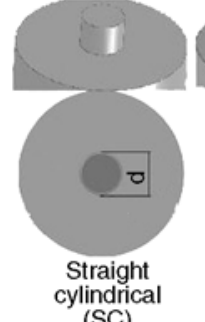

a)

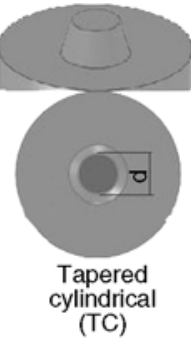

b)

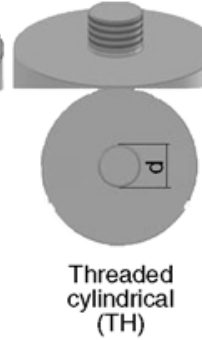

c)

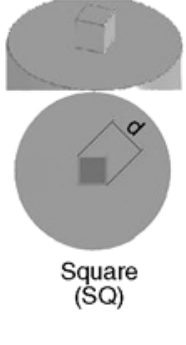

d)
Figure 4. FSSW tool profile and pin size $(d)$ : a) straight cylindrical, b) tapered cylindrical, c) threaded cylindrical, d) square

ure 4). In straight cylindrical, tapered cylindrical and threaded cylindrical pins, the pin diameters was determined by measuring the bottom diameter of the pin. In the square pin, the pin diameter was determined by measuring the diagonal lengh of the bottom of the pin. A standard M8 thread cylindrical pin was formed. Then, the pin of the tool was milled to a $7.5 \mathrm{~mm}$ diameter. The tool dimensions and their ranges employed in this study are given in Table 1. In this study, the welding parameters were selected from a previous publication. Optimum parameters obtained previously were selected for the experiments. The welding parameters were constant as $900 \mathrm{rpm}$ tool rotational speed, 105 seconds dwell time and 50 seconds delay before retracting the tool. The rotating tool plunged into the upper sheet with a $0.33 \mathrm{~mm} / \mathrm{s}$ plunge rate down to a $0.20 \mathrm{~mm}$ depth at an accuracy of $\pm 0.02 \mathrm{~mm}$ [35]. The stirring phase of FSSW started with the completion of the tool plunging. In this phase, the tool rotated without plunging. The duration of this phase is called the dwell time. Upon reaching of the predetermined dwell time, the rotation of the tool was immediately stopped. The tool stayed in the weld zone for 50 seconds and then it was retracted. All the welding operations were done at the room temperature. Before welding each specimen the pin and the shoulder of the tool were cooled to the room temperature.

Welded lap-shear specimens were tested on an Instron machine at a constant crosshead speed of
$5 \mathrm{~mm} / \mathrm{s}$. The fracture load was recorded during the test. The lap-shear fracture load was obtained by averaging the strengths of 5 individual specimens, which were welded with identical welding parameters. As a result of these experiments, the effect of tool properties on the lap-shear fracture load were investigated.

Weld cross section appearence observations of the joints were done with a video spectral comparator at 12.88X magnification. For macroscopic structure studies, thin slices $(30 \mu \mathrm{m})$ were cut from the welded specimens using a Leica R6125 model rotary type microtome. These thin slices were investigated using a VSC-5000 model video spectral comparator. The photographs of the cross sections were obtained. So, the effect of tool properties on weld stir zone formation were investigated.

\section{Results and discussion}

The importance of the tool pin profile was shown in Figure 5. In these tests, each tool had a $7.5 \mathrm{~mm}$ pin diameter, a 5.5 pin length, $6^{\circ}$ shoulder angle and $30 \mathrm{~mm}$ shoulder diameter. The tapered cylindrical pin had a $15^{\circ}$ pin angle. The maximum fracture load was obtained with the tapered cylindrical pin (4032 N). The straight cylindrical pin profile gave the lowest fracture load $(3305 \mathrm{~N})$. The reason of this difference can be easily explained with the weld stir zone thicknesses which are shown in Figure 6 . The straight cylindrical pin and tapered cylindrical pins have the same pin diameter $(7.5 \mathrm{~mm})$, but the weld stir zone thickness obtained by these pins are different. The stir zone thickness of the straight cylindrical is $7.5 \mathrm{~mm}$ as shown in Figure 6a. The $15^{\circ}$ tapered cylindrical pin has a $8.4 \mathrm{~mm}$ weld stir zone thickness (Figure 6b).

These two photographs show that the tapered pin produced a bigger weld area. The lap-shear fracture

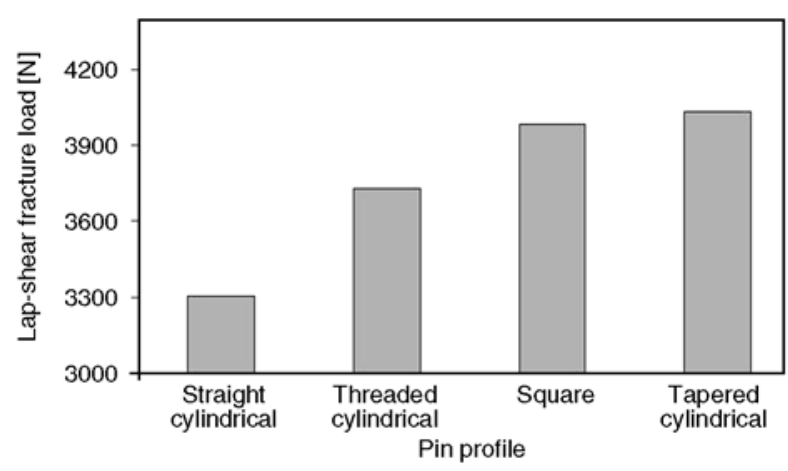

Figure 5. Lap shear fracture loads of different pin profiles 


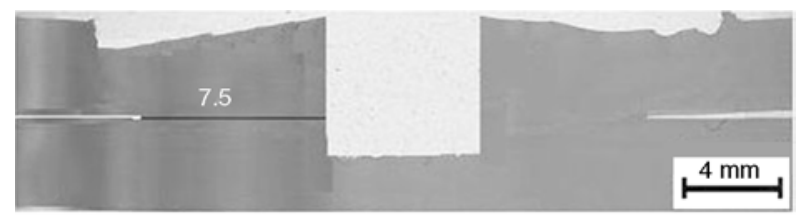

a)

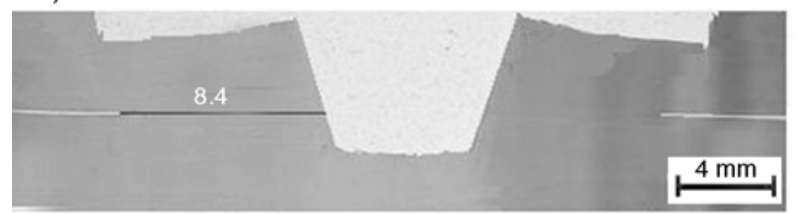

b)

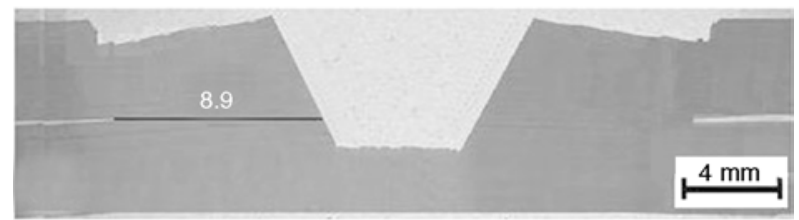

c)

Figure 6. The effect of pin angle on weld stir zone formation. (a) straight cylindrical pin, (b) $15^{\circ}$ pin angled tapered cylindrical pin and (c) $25^{\circ}$ pin angled tapered cylindrical pin.

force of a FSSW joint is directly proportional to the stir zone thickness and the weld bond area [30]. In FSSW of thermoplastics the welding force effect of a pin increases with the pin angle [13]. The tapered pin produces more friction heat and a bigger weld thickness as shown in Figure 6. The heat produced in the weld area is directly propertional to the welding force [36, 37]. A high welding force produces more heat and a bigger weld area which causes a high weld strength [24]. Therefore, the tapered pin produces a higher welding force than the straight cylindrical pin [13]. Therefore, the strength of the $15^{\circ}$ tapered pin is higher than that of the straight cylindrical pin. In Figure 5, it is shown that the threaded cylindrical pin's weld has a lower fracture load than the tapered pin's weld. This is an unexpected result. It was reported that the thread geometry [38], thread orientation [22] and thread pitch size [37] were important in metal FSSW operations. The effect of the lap-shear tensile fracture load and the tool pin angle on welding zone are shown in Figure 7 and Figure 6. Each tool had a $7.5 \mathrm{~mm}$ pin diameter, a $5.5 \mathrm{~mm}$ pin length, $6^{\circ}$ shoulder angle, $30 \mathrm{~mm}$ shoulder diameter and from 0 to $25^{\circ}$ pin angle. The photographs illustrate that the size of the keyhole which formed in the welding zone was directly dependent on the pin profile. The wall slope of the keyhole changed with the pin angle of the tool. The stir zone thickness is $7.5 \mathrm{~mm}$ for the

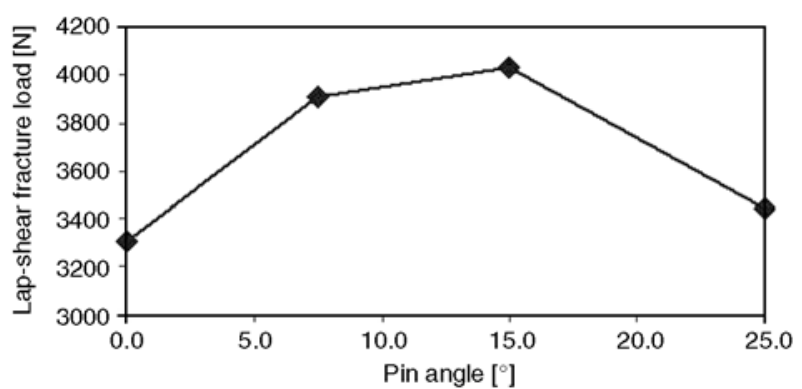

Figure 7. The effect of pin angle on the lap-shear fracture load

straight cylindrical pin, $8.4 \mathrm{~mm}$ for the $15^{\circ}$ pin angled tapered pin and $8.9 \mathrm{~mm}$ for the $25^{\circ}$ pin angled tapered pin. The tapered pins created thicker stir zone s than the straight cylindrical pin. The straight cylindrical pin which had a $0^{\circ}$ pin angle gave the least fracture load. The fracture load increased with the pin angle up to $15^{\circ}$ and then the fracture load reduced with the bigger pin angle. The stir zone thickness increased with the pin angle as shown in Figure 6. Although the $25^{\circ}$ tapered cylindrical pin has a $8.9 \mathrm{~mm}$ weld stir zone thickness, weld strength was lower than the others. The $25^{\circ}$ tapered cylindrical pin has produced more heat than the other tools. So, excessive heat and pressure will cause breakage of the chain structure. An excessive pin angle causes extra high friction heating which lowers the weld strength FSSW of thermoplastics.

In order to determine the effect of the thread pitch length on polypropylene FSSW, four different threaded cylindrical pins were produced. These pins are shown in Figure 8. The diameter of the each pin was $7.5 \mathrm{~mm}$. The pitch length was varied between $0.8-2.0 \mathrm{~mm}$. The pin length was $5.5 \mathrm{~mm}$ at each
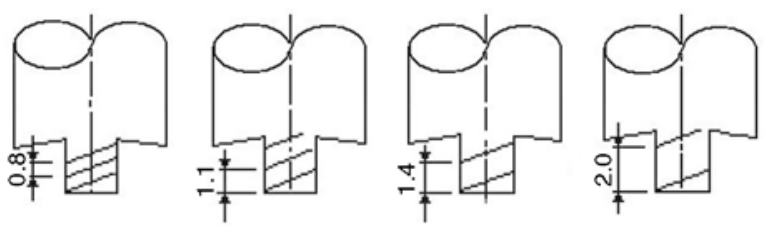

Figure 8. The geometry pitch length of theraded pins

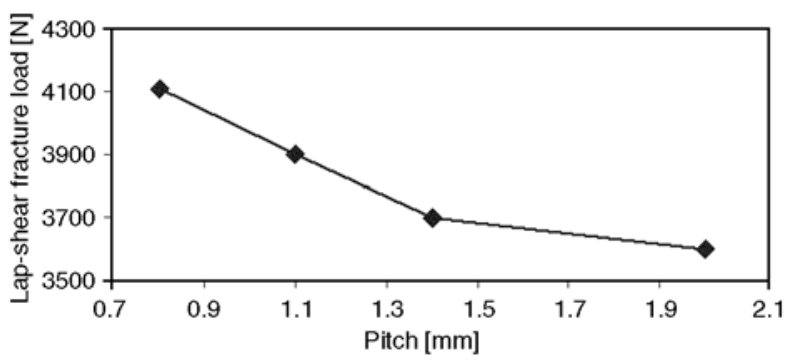

Figure 9. The effect of pitch length on lap shear fracture load 
tool. The $30 \mathrm{~mm}$ tool shoulder diameter, $0^{\circ}$ pin angle and $6^{\circ}$ shoulder angle were constant in the tools. The effect of pitch length on lap-shear fracture load is shown in Figure 9. The fracture load decreased with the pitch length. During FSSW operations material expulsion increased with the pitch. This lowers the weld strength. The threaded cylindrical pin shown in Figure 5 had a $1.25 \mathrm{~mm}$ pitch. The fracture load obtained with the $0.8 \mathrm{~mm}$ pitch (Figure 9) is higher than the result of the $15^{\circ}$ tapered pin and $1.25 \mathrm{~mm}$ pitch thread pin (Figure 5 and 9). That is why this pin gives a lower strength than the pin of $0.8 \mathrm{~mm}$ pitch. Increasing the threaded pitch punctures the materials as a drill [39]. So, shavings of material flow upward. In the FSSW process the most important point is that the shavings of the material must remain between the upper surface and the shoulder. If such conditions are not provided in the FSSW operation, welding will not occur. Therefore, threaded pitch was found to be important for the properties for FSSW.

Figure 10 shows the effect of the pin length on the weld fracture load. The tools used for these tests had a $30 \mathrm{~mm}$ shoulder diameter, $6^{\circ}$ shoulder angle, $15^{\circ}$ pin angle and $7.5 \mathrm{~mm}$ pin diameter. The pin length was varied between $3.8-6.5 \mathrm{~mm}$. The fracture load was nearly zero when the weld was made with the $3.8 \mathrm{~mm}$ pin length tool. A weld was not formed between the sheets. The pin worked as a drill. The pin hardly plunged into the lower workpiece. Most of the drilled material of the upper sheet was expelled out, so a very small weld stir zone formed which gave a very small fracture load. The fracture load increased with the pin length up to $5.5 \mathrm{~mm}$. The maximum lap-shear fracture load was obtained with the tool which had a $5.5 \mathrm{~mm}$ pin length. The pins which were longer than $5.5 \mathrm{~mm}$ gave smaller fracture loads. The weld cross sections

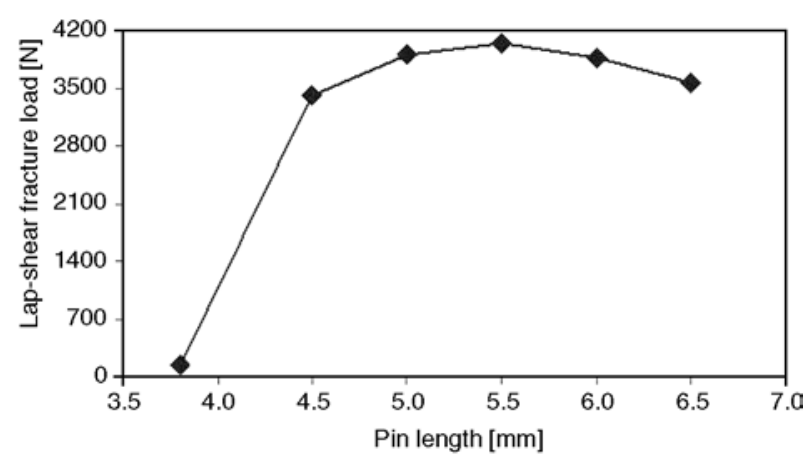

Figure 10. The effect of the pin length on the lap-shear fracture load

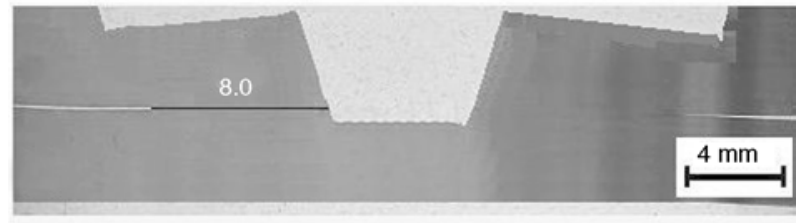

a)

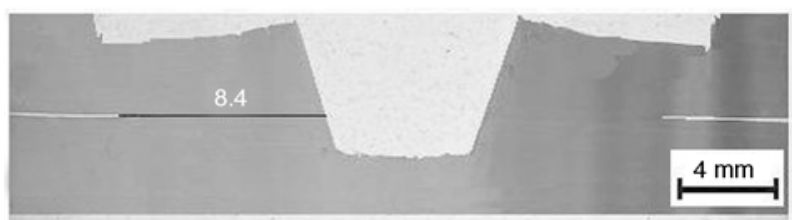

b)

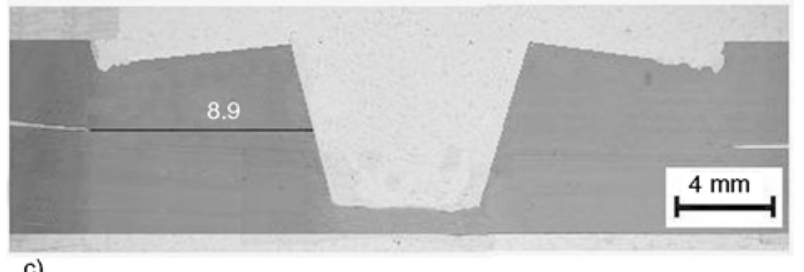

Figure 11. The effect of the pin length on the weld cross sections. (a) $4.5 \mathrm{~mm}$ pin length, (b) $5.5 \mathrm{~mm}$ pin length and (c) $6.5 \mathrm{~mm}$ pin length.

of these welds are shown in Figure 11. Therefore, it expelled the drilled material out of the welding zone. A small stir zone formed with this pin and only a $100 \mathrm{~N}$ fracture load was obtained as shown in Figure 11. The optimum pin length was determined as $5.5 \mathrm{~mm}$. Longer pin lengths produced bigger weld bond area but lowered the fracture load. The weld strength and the weld stir zone thickness increased with the pin length (Figure 11).

Figure 12 illustrates the effect of the shoulder diameter on the lap-shear fracture load. All the tools used for these tests had a 60 shoulder angle, $15^{\circ}$ pin angle, $7.5 \mathrm{~mm}$ pin diameter and $5.5 \mathrm{~mm}$ pin length. The shoulder diameter was varied between 10 and $35 \mathrm{~mm}$. The lap-shear tensile force increased with the shoulder diameter up to $30 \mathrm{~mm}$. Then the lap-shear fracture load reduced slightly with the increased shoul-

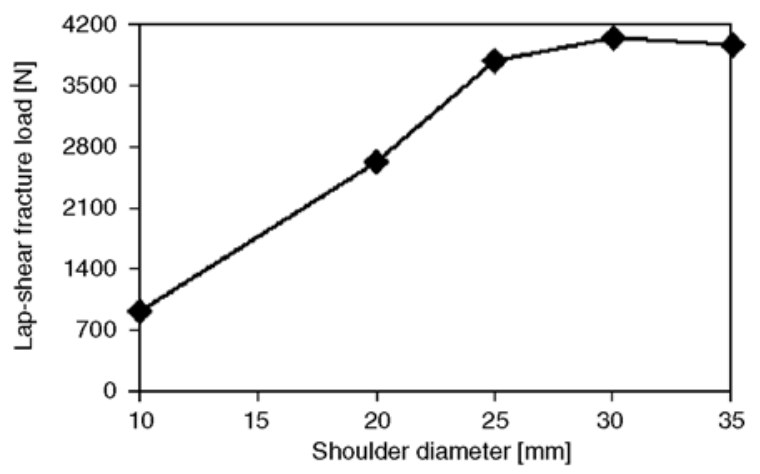

Figure 12. The effect of the shoulder diameter on the lapshear fracture load 


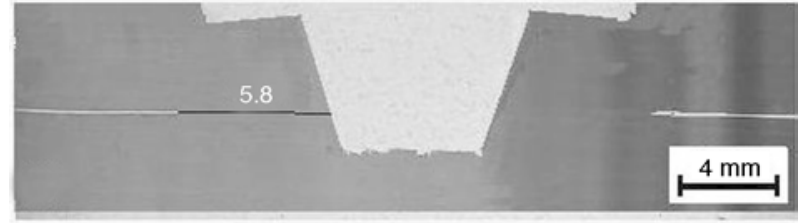

a)

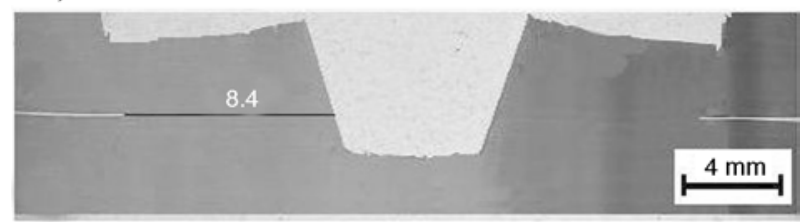

b)

Figure 13. The effect of the shoulder diameter on the weld cross sections. (a) $20 \mathrm{~mm}$ shoulder diameter and (b) $30 \mathrm{~mm}$ shoulder diameter.

der diameter. The load increased with the shoulder diameter because a big shoulder produced more friction heat [13] and a bigger stir zone thickness [33] as shown in Figure 12. The best load was obtained with the $30 \mathrm{~mm}$ shoulder diameter. The weld stir zone thickness increased with the shoulder diameter as shown in Figure 13. The shoulder diameter is understood to be very important for produced the heat and pressure. FSSW process must be selected the most suitable diameter of the shoulder for weld quality.

The effect of the shoulder concavity angle on the weld strength was shown in Figure 14. Each tool used for these tests had a $30 \mathrm{~mm}$ shoulder diameter, $15^{\circ}$ pin angle, $7.5 \mathrm{~mm}$ pin diameter and $5.5 \mathrm{~mm}$ pin length. The shoulder concavity angle was varied between $0.8-2.0 \mathrm{~mm}$. The fracture load increased with the shoulder angle. The best load was obtained with the $6^{\circ}$ shoulder angle. Increasing the shoulder angle beyond the $6^{\circ}$ angle caused a decrease in the weld strength. Therefore, a very small stir zone thickness and a small fracture load were obtained. If the shoulder angle is above this angle a smaller weld strength was obtained. The flat shoulder didn't produce a healthy weld stir zone, because during the stirring period of the welding operation the stirred

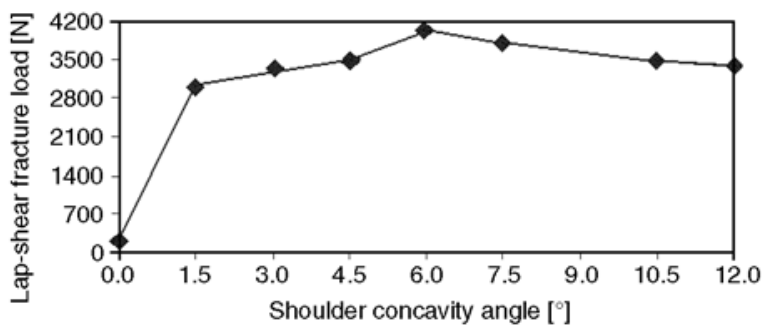

Figure 14. The effect of the shoulder angle on the lap-shear fracture load

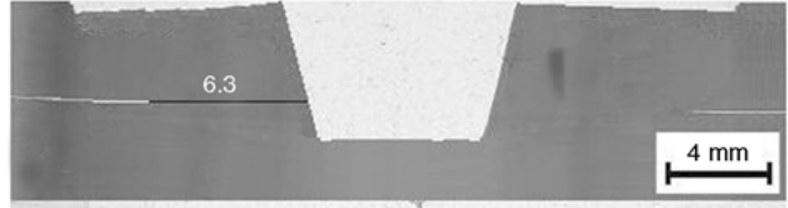

a)

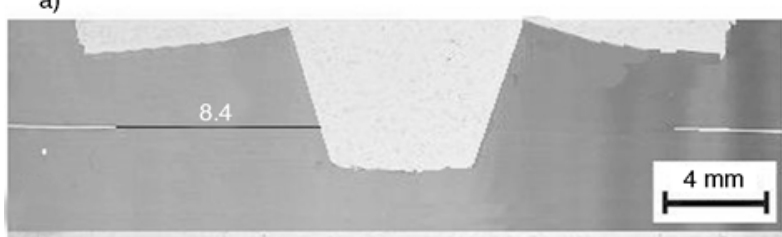

b)

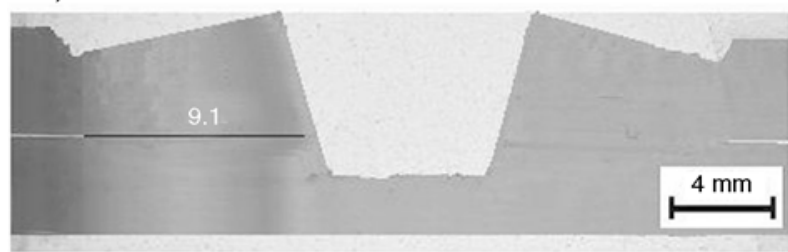

c)

Figure 15. The effect of the shoulder angle on the joint cross section, (a) $1.5^{\circ}$ shoulder angle tool, (b) $6^{\circ}$ shoulder angle tool and (c) $12^{\circ}$ shoulder angle tool

material was expelled out. A zero degree angle of the shoulder mustn't be used in FSSW experiments. In this study each mechanical test diagram shows an extremum. The lap-shear fracture load increases with the pin angle (Figure 15), the pin length (Figure 10), the shoulder diameter (Figure 12) and the shoulder concavity angle (Figure 14). All these diagrams indicate that there is an optimum value for each tool geometry variable. When the variable value exceeds the critical value, the weld strength starts decreasing. The size of the weld increased continously with the pin geometry variable (Figures 6 , 11, 13 and 15). For example, the weld stir zone thickness increased with the pin angle (Figure 6). The lap-shear fracture load reached its highest value with the $15^{\circ}$ pin angle (Figure 7). The fracture load of the $25^{\circ}$ pin is less than the $15^{\circ} \mathrm{pin}$. Although the $25^{\circ}$ pin had a bigger weld thickness than the $15^{\circ}$ pin (Figure 6), a lower fracture load was obtained with it. The reason of this strength difference is due to the chain scission [40]. Chain scission lowers the strength of a thermoplastic material [41]. If a molten thermoplastic material is heated to a high temperature and then a high pressure is applied to it, a decrease in the molecular weight of the material occurs [40]. The mechanical properties of thermoplastics decrease with lowering the molecular weight [42]. In FSSW the welding tool produces a compressive pressure 
in the weld zone [27]. In FSSW of thermoplastics the material in the weld area melts [13]. Very high temperatures were recorded in FSW of plastics [15, 43]. High melt temperatures and high welding forces cause chain scission in the welding zone of the plastics which lowers the weld strength [44].

The physical properties of a polymer are strongly dependent on the size or length of the polymer chain. For example, as chain length is increased, melting and boiling temperatures increase quickly. Weld strength also tends to increase with chain length, as does the viscosity, or resistance to flow, of the polymer in its melt state. FSSW process produces high temperature and pressure. But excessive heat and pressure will cause to break the chain structure. Most of molten material was expelled out, so a very small weld stir zone formed which gave a very small fracture load. Thus, a reduction in weld strength occurs. In the friction stir welding is very important to check the excessive heat and pressure. Furtermore, tool geometry is very important in the production of heat and pressure.

\section{Conclusions}

The following results were derived from this study:

- The biggest tensile strength were obtained with threaded tool (Pitch length $0.8 \mathrm{~mm}, 7.5 \mathrm{~mm}$ pin diameter, $5.5 \mathrm{~mm}$ pin length, $30 \mathrm{~mm}$ shoulder diameter and $6^{\circ}$ shoulder angle.

- In polypropylene FSSW, the weld tool geometry affects stir zone formation and weld lap-shear fracture load.

- The optimum straight tool geometry for $4 \mathrm{~mm}$ thick sheets was determined as $7.5 \mathrm{~mm}$ pin diameter, $15^{\circ}$ pin angle, $5.5 \mathrm{~mm}$ pin length, $30 \mathrm{~mm}$ shoulder diameter and $6^{\circ}$ shoulder angle.

- The weld strength obtained with a threaded pin decreases with the pitch. Pitch length of threaded pins are very important for the weld quality and the weld strength.

- Chain scission can occur in polypropylene FSSW, if excessive high friction heating is created in the weld zone.

- Excessive heat and pressure will cause to break the chain structure. So, the importance of controlling excessive heat and pressure was emerged.

\section{Acknowledgements}

This work was supported by Scientific Research Project Program of Marmara University (Project No. FEN-C-DRP010710-230).

\section{References}

[1] Thomas W. M., Nicholas E. D.: Friction stir welding for the transportation industries. Materials and Design, 18, 269-273 (1997). DOI: 10.1016/S0261-3069(97)00062-9

[2] Chowdhury S. M., Chen D. L., Bhole S. D., Cao X.: Tensile properties of a friction stir welded magnesium alloy: Effect of pin tool thread orientation and weld pitch. Materials Science and Engineering A, 527, 6064-6075 (2010). DOI: $10.1016 /$ j.msea.2010.06.012

[3] Knipling K. E., Fonda R. W.: Texture development in the stir zone of near- $\alpha$ titanium friction stir welds. Scripta Materialia, 60, 1097-1110 (2009).

DOI: $10.1016 /$ j.scriptamat.2009.02.050

[4] Meran C.: The joint properties of brass plates by friction stir welding. Materials and Design, 27, 719-726 (2006).

DOI: $10.1016 /$ j.matdes.2005.05.006

[5] Zhu X. K., Chao J. Y.: Numerical simulation of transient temperature and residual stresses in friction stir welding of 304L stainless steel. Journal of Materials Processing Technology, 6, 125-133 (2004). DOI: $10.1016 /$ j.jmatprotec.2003.10.025

[6] Chung Y. D., Fujii H., Ueji R., Tsuji N.: Friction stir welding of high carbon steel with excellent toughness and ductility. Scripta Materialia, 63, 223-226 (2007). DOI: 10.1016/j.scriptamat.2010.03.060

[7] Kiss Z., Czigány T.: Microscopic analysis of the morphology of seams in friction stir welded polypropylene. Express Polymer Letters, 6, 54-62 (2012). DOI: $10.3144 /$ expresspolymlett.2012.6

[8] Hancock R.: Friction welding of aluminium cuts energy cost by $99 \%$. Welding Journal, 83, 40 (2004).

[9] Lin P-C., Pan J., Pan T.: Failure modes and fatigue life estimations of spot friction welds in lap-shear specimens of aluminum 6111-T4 sheets. Part 1: Welds made by a concave tool. International Journal of Fatigue, 30, 74-89 (2008). DOI: $10.1016 /$ j.ijfatigue.2007.02.016

[10] Merzoug M., Mazari M., Berrahal L., Imad A.: Parametric studies of the process of friction spot stir welding of aluminium 6060-T5 alloys. Materials and Design, 31, 3023-3028 (2010). DOI: $10.1016 /$ j.matdes.2009.12.029

[11] Chen Y. C., Nakata K.: Effect of tool geometry on microstructure and mechanical properties of friction stir lap welded magnesium alloy and steel. Materials and Design, 30, 3913-3919 (2009). DOI: $10.1016 / \mathrm{j}$. matdes.2009.03.007 
[12] Khan M. I., Kuntz M. L., Su P., Gerlich A., North T., Zhou Y.: Resistance and friction stir spot welding of DP600: A comparative study. Science and Technology of Welding and Joining, 12, 175-182 (2007).

DOI: $10.1179 / 174329307$ X159801

[13] Bilici M. K., Yükler A. I.: Influence of tool geometry and process parameters on macrostructure and static strength in friction stir spot welded polyethylene sheets. Materials and Design, 33, 145-152 (2012). DOI: $10.1016 /$ j.matdes.2011.06.059

[14] Arici A., Mert S.: Friction stir spot welding of polypropylene. Journal of Reinforced Plastics and Composites, 27, 2001-2004 (2008).

DOI: $10.1177 / 0731684408089134$

[15] Oliveria P. H. F., Amancio-Filho S. T., dos Santos J. F., Hage E.: Preliminary study on the feasibility of friction spot welding in PMMA. Materials Letters, 64, 2098-2101 (2010).

DOI: $10.1016 /$ j.matlet.2010.06.050

[16] Bilici M. K., Yükler A. I., Kurtulmuş M.: The optimization of welding parameters for friction stir spot welding of high density polyethylene sheets. Materials and Design, 32, 4074-4079 (2011).

DOI: $10.1016 /$ j.matdes.2011.03.014

[17] Rodrigues D. M., Loureiro A., Leitao C., Leal R. M., Chaparro B.M., Vilaça P.: Influence of friction stir welding parameters on the microstructural and mechanical properties of AA 6016-T4 thin welds. Materials and Design, 30, 1913-1921 (2009).

DOI: $10.1016 /$ j.matdes.2008.09.016

[18] Mishra R. S., Ma Z. Y.: Friction stir welding and processing. Materials Science and Engineering R: Reports, 50, 1-78 (2005).

DOI: 10.1016/j.mser.2005.07.001

[19] Su P., Gerlich A., North T. H.: Friction stir spot welding of aluminum and magnesium alloy sheets. SAE Technical Paper. 2005-01-1255 (2005).

DOI: $10.4271 / 2005-01-1255$

[20] Kulekci M. K., Şik A., Kaluç E.: Effects of tool rotation and pin diameter on fatigue properties of friction stir welded lap joints. The International Journal of Advanced Manufacturing Technology, 36, 877-882 (2008).

DOI: $10.1007 / \mathrm{s} 00170-006-0901-\mathrm{Z}$

[21] Hirasawa S., Badarinarayan H., Okamoto K., Tomimura T., Kawanami T.: Analysis of effect of tool geometry on plastic flow during friction stir spot welding using particle method. Journal of Materials Processing Technology, 210, 1455-1463 (2010).

DOI: $10.1016 /$ j.jmatprotec.2010.04.003

[22] Chowdhury S. M., Chen D. L., Bhole S. D., Cao X.: Effect of pin tool thread orientation on fatigue strength of friction stir welded AZ31B-H24 Mg butt joints. Procedia Engineering, 2, 825-833 (2010).

DOI: 10.1016/j.proeng.2010.03.089
[23] Tozaki Y., Uematsu Y., Tokaji K.: Effect of tool geometry on microstructure and static strength in friction stir spot welded aluminium alloys. International Journal of Machine Tools and Manufacture, 47, 22302236 (2007).

DOI: 10.1016/j.ijmachtools.2007.07.005

[24] Vijay S. J., Murugan N.: Influence of tool pin profile on the metallurgical and mechanical properties of friction stir welded $\mathrm{Al}-10$ wt.\% $\mathrm{TiB}_{2}$ metal matrix composite. Materials and Design, 31, 3585-3589 (2010). DOI: $10.1016 /$ j.matdes.2010.01.018

[25] Yang Q., Mironov S., Sato Y. S., Okamoto K.: Material flow during friction stir spot welding. Materials Science and Engineering A, 527, 4389-4398 (2010).

DOI: $10.1016 /$ j.msea.2010.03.082

[26] Badarinarayan H., Yang Q., Zhu S.: Effect of tool geometry on static strength of friction stir spot-welded aluminum alloy. International Journal of Machine Tools and Manufacture, 49, 142-148 (2009).

DOI: $10.1016 /$ j.ijmachtools.2008.09.004

[27] Gerlich A., Yamamoto M., North T. H.: Local melting and cracking in Al 7075-T6 and Al 2024-T3 friction stir spot welds. Science and Technology of Welding and Joining, 12, 472-480 (2007).

DOI: $10.1179 / 174329307 X 213873$

[28] Tozaki Y., Uematsu Y., Tokaji K.: Effect of processing parameters on static strength of dissimilar friction stir spot welds between different aluminium alloys. Fatigue and Fracture of Engineering Materials and Structures, 30, 143-148 (2007).

DOI: $10.1111 /$ j.1460-2695.2006.01096.x

[29] Badarinarayan H., Shi Y., Li X., Okamoto K.: Effect of tool geometry on hook formation and static strength of friction stir spot welded aluminum 5754-O sheets. International Journal of Machine Tools and Manufacture, 49, 814-823 (2007).

DOI: $10.1016 /$ j.ijmachtools.2009.06.001

[30] Feng Z., Santella M. L., David S., Steel R. J., Packer S. M., Pan T., Kuo M., Bhatnagar R. S.: Friction stir spot welding of advanced high-strength steels - A feasibility study. SAE Technical Paper, 2005-01-1248 (2005). DOI: $10.4271 / 2005-01-1248$

[31] Goodarzi M., Marashi S. P. H., Pouranvari M.: Dependence of overload performance on weld attributes for resistance spot welded galvanized low carbon steel. Journal of Materials Processing Technology, 209, 4379-4384 (2009).

DOI: $10.1016 /$ j.jmatprotec.2008.11.017

[32] ANSI/AWS C1.4:2009: Specification for resistance welding of coated and uncoated carbon and low alloy steels (2007).

[33] Elangovan K., Balasubramanian V.: Influences of tool pin profile and welding speed on the formation of friction stir processing zone in AA2219 aluminium alloy. Journal of Materials Processing Technology, 200, 163-175 (2008).

DOI: $\underline{10.1016 / j . j m a t p r o t e c .2007 .09 .019}$ 
[34] Yuan W., Mishra R. S., Webb S., Chen Y. L., Carlson B., Herling D. R., Grant G. J.: Effect of tool design and process parameters on properties of $\mathrm{Al}$ alloy 6016 friction stir spot welds. Journal of Materials Processing Technology, 211, 972-977 (2011).

DOI: $\underline{10.1016 / \mathrm{j} . j m a t p r o t e c .2010 .12 .014}$

[35] Bilici M. K.: Application of Taguchi approach to optimize friction stir spot welding parameters of polypropylene. Materials and Design, 35, 113-119 (2012). DOI: $10.1016 / \mathrm{j}$. matdes.2011.08.033

[36] Awang M., Mucino V. H., Feng Z., David S. A.: Thermo-mechanical modeling of friction stir spot welding (FSSW). SAE International, 2006-01-1392 (2006).

DOI: $10.4271 / 2006-01-1392$

[37] Ma N., Kunugi A., Hirashima T., Okubo K., Kamioka M.: FEM simulation for friction spot joining process. Welding International, 23, 9-14 (2009). DOI: $10.1080 / 09507110802348892$

[38] Hattingh D. G., Blignault C., van Niekerk T. I., James M. N.: Characterization of the influences of FSW tool geometry on welding forces and weld tensile strength using an instrumented tool. Journal of Materials Processing Technology, 203, 46-57 (2008). DOI: 10.1016/j.jmatprotec.2007.10.028
[39] Boz M., Kurt A.: The influence of stirrer geometry on bonding and mechanical properties in friction stir welding process. Materials and Design, 25, 343-347 (2004).

DOI: $10.1016 / \mathrm{j}$. matdes.2003.11.005

[40] da Costa H. M., Ramos V. D., Rocha M. C. G.: Rheological properties of polypropylene during multiple extrusion. Polymer Testing, 24, 86-93 (2005).

DOI: $10.1016 /$ j.polymertesting.2004.06.006

[41] Capone C., Di Landro L., Inzoli F., Penco M., Sartore L.: Thermal and mechanical degradation during polymer extrusion processing. Polymer Engineering and Science, 47, 1813-1819 (2007).

DOI: $10.1002 /$ pen.20882

[42] Sung J. H., Lim S. T., Kim C. A., Chung H., Choi H. J.: Mechanical degradation kinetics of poly(ethylene oxide) in a turbulent flow. Korea-Australia Rheology Journal, 16, 57-62 (2004).

[43] Aydin M.: Effects of welding parameters and pre-heating on the friction stir welding of UHMW-polyethylene. Polymer-Plastics Technology and Engineering, 49, 595-601 (2010). DOI: $10.1080 / 03602551003664503$

[44] Gan Y. X., Salomon D., Reinbolt M.: Friction stir processing of particle reinforced composite materials. Materials, 3, 329-350 (2010).

DOI: $10.3390 / \mathrm{ma3} 010329$ 